SCIREA Journal of Civil Engineering and

Building Construction

http://www.scirea.org/journal/CEBC

February 10, 2022

SCIREA

Volume 7, Issue 1, February 2022

https://doi.org/10.54647/cebc56077

\title{
Sensitivity analysis on influence factors of reinforced tailings accumulation dam
}

\author{
Zhang Xin, Li Donhze, Ma qigong, Fan xiangrong, Liu yunhao \\ College of Civil Engineering, Liaoning Technical University, Fuxin 123000, China
}

\begin{abstract}
In order to find out the sensitivity of influencing factors on the slope stability of geogrid reinforced tailings dam, the single index multi factor numerical simulation test was designed by orthogonal method, Five influencing factors including elastic modulus $(E)$, laying length $(L)$, laying spacing $(d)$, pseudo-cohesion of reinforcement-tailings interface $\left(c_{\mathrm{if}}\right)$ and pseudo friction angle of reinforcement-tailings interface $\left(\varphi_{\mathrm{if}}\right)$ were selected .The $\mathrm{L}_{25}\left(5^{6}\right)$ orthogonal table 25 groups of scheme was designed, numerical calculation was carried out by finite element strength reduction method to determine the safety factor and analyze the sensitivity of factors affecting the stability of stiffened tailings dam. The results show that the order of sensitivity of influencing factors of reinforced tailings dam is laying length $(L)>$ laying spacing $(d)>$ elastic modulus $(E)>$ pseudo-cohesion $\left(c_{\mathrm{if}}\right)>$ pseudo friction angle $\left(\varphi_{\mathrm{if}}\right)$; The significance test results show that the laying length $(L)$ and laying spacing $(d)$ have a very significant impact, the elastic modulus $(E)$ and pseudo-cohesion $\left(c_{\text {if }}\right)$ have a significant impact, and the pseudo friction angle $\left(\varphi_{\mathrm{if}}\right)$ the impact is not very significant; Among them, the sensitivity ranking of reinforcement influencing factors of range analysis results is consistent with the significance results of analysis of variance, which verifies the reliability of numerical simulation results.
\end{abstract}


Keywords: tailings; slope stability; range analysis; variance analysis

\section{Introduction}

The safety and stability of tailings dam has always been the concern of engineers. In recent years, the reinforcement of tailings dam with geosynthetics is a very effective technical means (Yin et al., 2018; Tan et al., 2018; Yi et.al., 2019). The research methods for the stability of tailings dam mainly include experiment, theoretical analysis and numerical calculation. Among them, numerical calculation is an effective supplement and verification to the experimental research, and can obtain data and laws that cannot be obtained by traditional methods(Zheng et al., 2019; Du et al., 2021; Ning et.al., 2010).

Scholars at home and abroad have done a lot of work in studying the numerical calculation of tailings dam stability: Xie et al. (2014) established a finite element model based on Mohr Coulomb criterion by using ABAQUS software on the basis of finite element strength reduction method to analyze the change law of accumulation dam of Wujiagou tailings pond. Zhang et al. (2014) simulated the macro and micro mechanical characteristics of a tailings dam slope before and after tailings filling by using the discrete continuous coupling analysis method of finite difference and discrete element. Zhang et al.(2015) based on the discrete element theory, conducted biaxial test with $\mathrm{PFC}^{2 \mathrm{D}}$ numerical simulation software to obtain the micromechanical parameters of tailings and the deformation characteristics of tailings dam. Yang et al. (2021) obtained the instability mechanism of high tailings dam through theoretical analysis and numerical simulation, and suggested using strength reduction method to analyze the stability of high tailings dam. Wang et al. (2017) systematically studied the static and dynamic stability of fine-grained upstream tailings dam by comprehensively using various methods such as geotechnical test, theoretical analysis and numerical simulation.

Deng et al(2016) used slide of stripe theory and GMS of finite difference theory to analyze tailings dam stability. A numerical simulation model of the lens body in the tailings dam is established. Lin et al(2020) analyzed the seepage control effect of the geotechnical mat of the tailings dam by saturated seepage finite element method. The stability of the dam slope was analyzed by strength reduction. Wei et al. (2014) uses horizontal stripe scoring and numerical simulation, The feasibility of end-reeling geogrids for tailings accumulation dam reinforcement is studied. Wang et al. (2018) based on the limit balance method, the stability calculation under natural working conditions, rainstorm conditions, seismic conditions and 
rainstorm + seismic conditions is carried out; Abaqus is used to compare the stability of the tailings dam body under the above working conditions. Liu et al. (2018) proposed a drainage system that combines horizontal drainage pipes and upwardly curved slotted pipes, And applied to the design of the anti-seepage system of a tailings dam, the anti-seepage effect is improved. Yu et al. (2013) under planar strain conditions, the stability of tailings dams was analyzed by finite element limit balance method, and Hooke-Jeeves was used to give an example of stability analysis of tailings dam engineering. In summary, the above scholars mainly use numerical calculation methods such as finite element, finite difference and discrete element to analyze the stability of tailings dams, but there are not many numerical calculations to study the stability of reinforced tailings dams, and numerical analysis of the sensitivity of the influencing factors of reinforced tailings dams is rarely reported.

In this paper, the reinforcement design is carried out for the $175 \mathrm{~m}$ elevation of the main dam of Fengshuigou tailings pond in Qidashan concentrator of Angang. The sensitivity analysis of the influencing factors of different reinforced tailings dam is completed by numerical simulation, and the influence of reinforcement laying length, spacing, reinforcement strip parameters and external slope ratio of the dam on the stability of the tailings dam is analyzed,combined with the previous reinforcement laying research and specification requirements, the appropriate laying process is designed, and the reasonable reinforcement control parameters in the structural design of reinforced tailings are determined.

\section{Project overview}

This paper takes the main dam of Fengshuigou tailings pond in Qidashan as an example. The initial dam of the main dam of Fengshuigou tailings pond is a permeable rockfill dam with a dam crest width of $4 \mathrm{~m}$, an upstream slope ratio of 1:1.85, a downstream slope ratio of $1: 2$, a dam bottom elevation of $55 \mathrm{~m}$, a dam crest elevation of $76 \mathrm{~m}$ and a dam height of $21 \mathrm{~m}$. A 4 $\mathrm{m}$ wide berm is set at the elevation of $66 \mathrm{~m}$ on the outer slope of the initial dam, and the dam foundation is located on the gravel layer.The stacking dam of tailings pond is constructed by the upstream method, with multi pipe decentralized ore drawing. The height of per level sub dam is about $5 \mathrm{~m}$. The stacking dam of increase the height to $175 \mathrm{~m}$ is selected for numerical calculation. The average outer slope ratio of the stacking dam is about 1:5. At this time, the maximum dam height is $120 \mathrm{~m}$, the total storage capacity is about 684 million $\mathrm{m}^{3}$, and the tailing pond is first-grade. As shown in Figure 1,is the cross-sectional dimensions of the main 
dam of Fengshuigou tailings pond are schematic diagram.

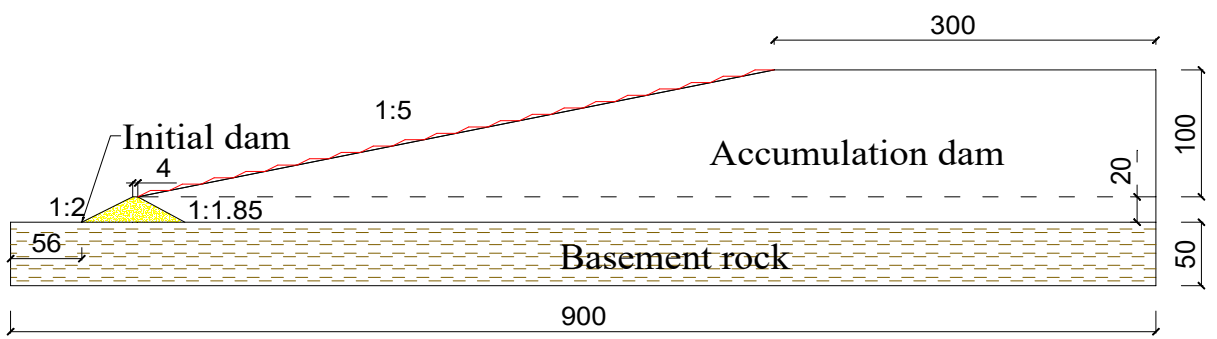

Figure 1 Section size of main dam of Fengshuigou tailings pond (Unit: m)

\section{Establishment of numerical model of reinforced tailings dam}

\subsection{Model building assumptions}

Based on the comprehensive analysis of the reinforcement measures and the reinforcement particularity of tailings accumulation dam, the scheme design of reinforcement measures is carried out according to the principle of "technical feasibility, safety and reliability, economic rationality and convenient implementation". In the design of reinforcement scheme, it is assumed that: (1) the tailings dam is in normal operation; (2) The reinforcement is in close contact with the tailings, the overall deformation of the reinforced tailings structure is coordinated, and the reinforcement has no relative sliding between the tailings; (3) The mechanical properties of reinforcement materials are intact, and there is no fracture, damage and other conditions during the construction of reinforced tailings.

\subsection{Selection of reinforcement parameters}

\section{(1) Tailings material parameters}

During modeling, the tailings accumulation dam model is properly simplified, and the model simplification follows the two modeling principles of "controlling the model scale" and "maintaining the accuracy of calculation results". It is considered that the tailings dam is formed by the accumulation of all tailings, and the physics mechanics indexes at different positions of the tailings dam are shown in Table 1.

Table 1 Physics mechanics indexes of different positions of tailings dam

\begin{tabular}{cccccc}
\hline Category & $\begin{array}{c}\text { Natural bulk } \\
\text { density } /\left(\mathrm{kN} / \mathrm{m}^{3}\right)\end{array}$ & $\begin{array}{c}\text { Pseudo } \\
\text { friction } / \mathrm{kPa}\end{array}$ & $\begin{array}{c}\text { Pseudo friction } \\
\text { angle } /{ }^{\circ}\end{array}$ & $\begin{array}{c}\text { Poisson's } \\
\text { ratio }\end{array}$ & $\begin{array}{c}\text { Elastic modulus } \\
/ \mathrm{kPa}\end{array}$ \\
\hline $\begin{array}{c}\text { Initial dam } \\
\text { Total }\end{array}$ & 25 & 9.4 & 38.5 & 0.35 & $3.5 \times 10^{5}$ \\
$\begin{array}{c}\text { tailings } \\
\text { Bedrock }\end{array}$ & 17.4 & 1 & 33.4 & 0.25 & $1.6 \times 10^{5}$ \\
\hline
\end{tabular}




\section{(2) Reinforcement parameters}

In this paper, the main mechanical parameter of reinforcement is tensile strength, the value range of elastic modulus $E$ is $0.5-15 \mathrm{GPa}$. In the process of modeling, the elastic modulus $E$ is taken as the input mechanical parameter of reinforcement, and the elastic-plastic constitutive model of reinforcement material is given.

\section{(3) Strength index of reinforcement tailings interface}

Referring to the author's laboratory pull-out test results (Yi Fu et al., 2020), in the actual engineering design, the interface strength index between reinforcement and tailings take the minimum value in the test, and the values of pseudo-cohesion of reinforcement-tailings interface $\left(c_{\mathrm{if}}\right)$ and pseudo friction angle of reinforcement-tailings interface $\left(\varphi_{\mathrm{if}}\right)$ between reinforceme nt and tailings are respectively $5-25 \mathrm{kPa}$ and $10-30^{\circ}$.

\subsection{Boundary conditions and establishment of numerical model}

The tailings dam is surrounded by mountains on three sides and belongs to valley type tailings pond. Considering the distribution of tailings dam in the longitudinal section of the central axis, a numerical model is established. The left and right ends of the model are horizontally constrained, the bottom end is fixed, and the upper end is a free boundary. The model generalized processing the initial dam and tailings accumulation sub dam. The elevation of the initial dam crest is $75 \mathrm{~m}$, the elevation of the dam crest is $55 \mathrm{~m}$, and the outer slope ratio of the accumulation dam sub dam is about 1:5. The calculation diagram of the dam height profile of the main dam when it is raised to the elevation of $175 \mathrm{~m}$ is shown in Figure 2. The constitutive model of tailings is Mohr-Coulomb elastic-plastic model.

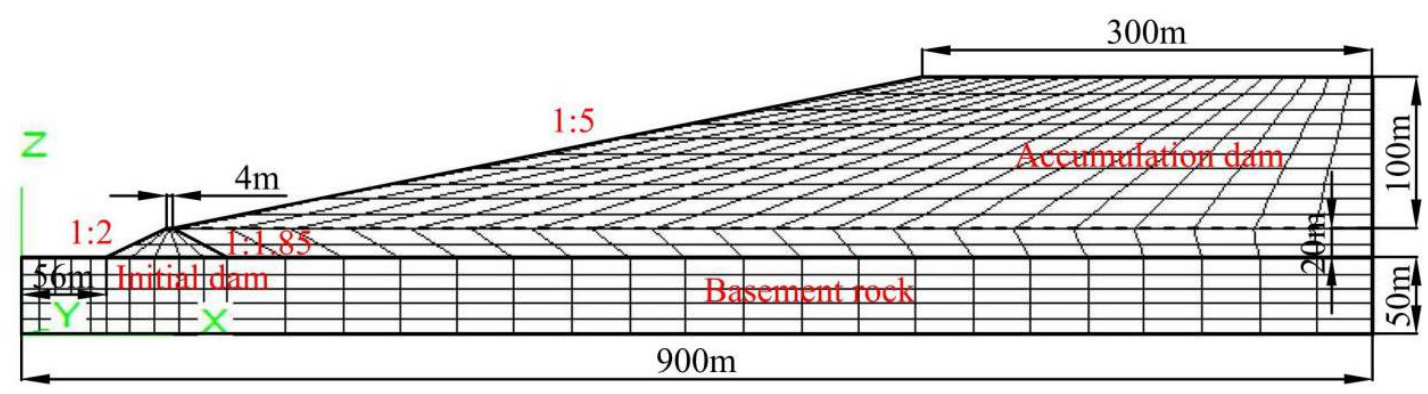

Figure 2 Establishment of finite element model

According to "Code for design of tailings facilities" (GB 50863-2013), the minimum anti sliding stability safety factor of first-class tailings pond under normal conditions is 1.30 . As shown in Figure 3, calculated by strength reduction method the safety factor of tailings dam without reinforcement is 1.94 , which meets the specification requirements. 
FoS

FoS value is : 1.94

Contour of Shear Strain Increment

Magfac $=0.000 \mathrm{e}+000$

Gradient Calculation

$4.2141 \mathrm{e}-007$ to $2.5000 \mathrm{e}-001$

$2.5000 \mathrm{e}-001$ to $5.0000 \mathrm{e}-001$

$5.0000 \mathrm{e}-001$ to $7.5000 \mathrm{e}-001$

$7.5000 \mathrm{e}-001$ to $1.0000 \mathrm{e}+000$

$1.0000 \mathrm{e}+000$ to $1.2500 \mathrm{e}+000$

$1.2500 \mathrm{e}+000$ to $1.5000 \mathrm{e}+000$

$1.5000 \mathrm{e}+000$ to $1.7500 \mathrm{e}+000$

$1.7500 \mathrm{e}+000$ to $2.0000 \mathrm{e}+000$

$2.0000 \mathrm{e}+000$ to $2.2160 \mathrm{e}+000$

Interval $=2.5 \mathrm{e}-001$

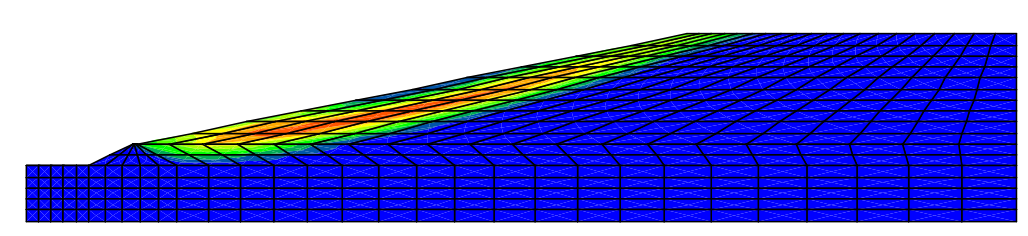

Figure3 Cloud chart of stability calculation of tailings dam with no reinforcement

\section{Sensitivity analysis of reinforcement factors of fill dam}

With tailings as filler, with the increase of the height of tailings dam, laying geosynthetics with a certain spacing can increase the stability of tailings dam, but the sensitivity of various influencing factors of reinforcement to the safety factor of tailings dam is unknown. The elastic modulus $(E)$, laying length $(L)$, laying spacing $(d)$, pseudo-cohesion $\left(c_{\mathrm{if}}\right)$ and pseudo friction angle $\left(\varphi_{\mathrm{if}}\right)$ five factors affecting reinforcementare considered from the engineering point of view according to Qidashan Fengshuigou tailings pond ,through orthogonal analysis, the sensitivity ranking of these five factors is determined, and the main factors affecting the stability of reinforced tailings dam are found out, in order to grasp the influence of the main influencing factors on the safety factor of the dam body and give full play to the effect of reinforcement of tailings dam.

\subsection{Orthogonal numerical test design}

Considering the elastic modulus $(E)$, laying length $(L)$, laying spacing $(d)$, pseudo-cohesion $\left(c_{\text {if }}\right)$ and pseudo friction angle $\left(\varphi_{\text {iff }}\right)$ there are 5 influencing factors in total, and 25 cases with 6 factors and 5 levels are designed for orthogonal analysis to determine the sensitivity ranking of each reinforcement influencing factor. The values of elastic modulus $(E)$ are $0.5 \mathrm{GPa}, 4 \mathrm{GPa}$, 7.5 GPa, $11 \mathrm{GPa}$ and $15 \mathrm{GPa}$; Laying length $(L)$ and laying spacing $(d)$ according to the actual situation of the main dam of Fengshuigou tailings pond, the laying length is $120 \mathrm{~m}, 150 \mathrm{~m}$, $180 \mathrm{~m}, 210 \mathrm{~m}$ and $240 \mathrm{~m}$, and the laying spacing is $1 \mathrm{~m}, 2 \mathrm{~m}, 3 \mathrm{~m}, 4 \mathrm{~m}$ and $5 \mathrm{~m}$; The pseudocohesion $\left(c_{\mathrm{if}}\right)$ and pseudo friction angle $\left(\varphi_{\text {if }}\right)$ values are $5 \mathrm{kPa}, 10 \mathrm{kPa}, 15 \mathrm{kPa}, 20 \mathrm{kPa}, 25 \mathrm{kPa}$ and respectively $10^{\circ}, 15^{\circ}, 20^{\circ}, 25^{\circ}$ and $30^{\circ}$. The $\mathrm{L}_{25}\left(5^{6}\right)$ orthogonal table is selected to arrange the equal level orthogonal test scheme. The levels of reinforcement influencing 
factors in the orthogonal test are shown in Table 2. The tailings accumulation model with different laying spacing of reinforcement materials is shown in Figure 4.

Table 2 Level table of influencing factors of reinforced dam

\begin{tabular}{|c|c|c|c|c|c|}
\hline \multirow{3}{*}{$\begin{array}{l}\text { Factor } \\
\text { level }\end{array}$} & \multicolumn{5}{|c|}{ Influence factor } \\
\hline & \multirow{2}{*}{$\begin{array}{c}\text { Reinforcement } \\
\text { parameters } \\
\text { Elastic modulus } E / \\
\text { GPa }\end{array}$} & \multicolumn{2}{|c|}{ Laying parameters } & \multicolumn{2}{|c|}{$\begin{array}{l}\text { Strength index of reinforcement- } \\
\text { tailings interface }\end{array}$} \\
\hline & & $\begin{array}{l}\text { Laying } \\
\text { length } L / \mathrm{m}\end{array}$ & $\begin{array}{c}\text { Laying } \\
\text { spacing } d / \mathrm{m}\end{array}$ & $\begin{array}{l}\text { Pseudo- } \\
\text { cohesion } c_{\text {iff }} / \\
\mathrm{kPa}\end{array}$ & $\begin{array}{l}\text { Pseudo friction } \\
\text { angle } \varphi_{\mathrm{if}} /{ }^{\circ}\end{array}$ \\
\hline 1 & 0.5 & 120 & 1 & 5 & 10 \\
\hline 2 & 4 & 150 & 2 & 10 & 15 \\
\hline 3 & 7.5 & 180 & 3 & 15 & 20 \\
\hline 4 & 11 & 210 & 4 & 20 & 25 \\
\hline 5 & 15 & 240 & 5 & 25 & 30 \\
\hline
\end{tabular}

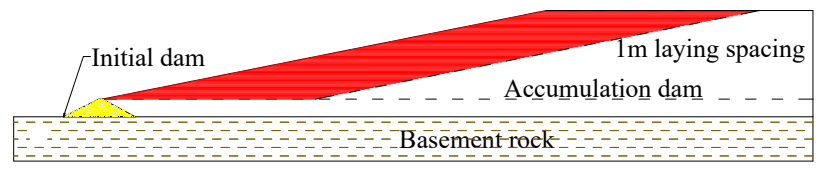

(a)The laying spacing is $1 \mathrm{~m}$

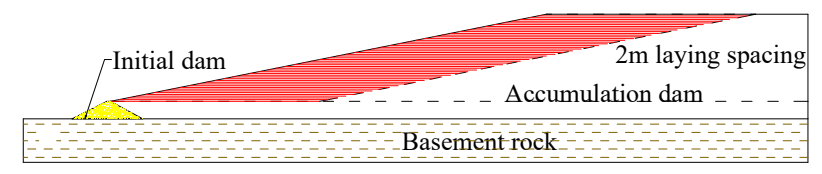

(b)The laying spacing is $2 \mathrm{~m}$

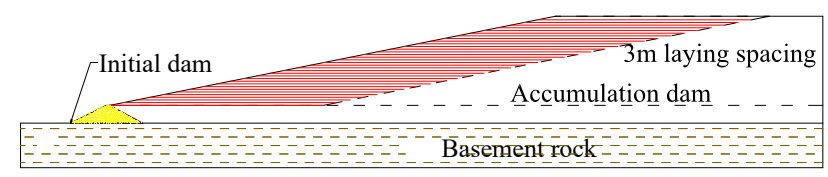

(c)The laying spacing is $3 \mathrm{~m}$

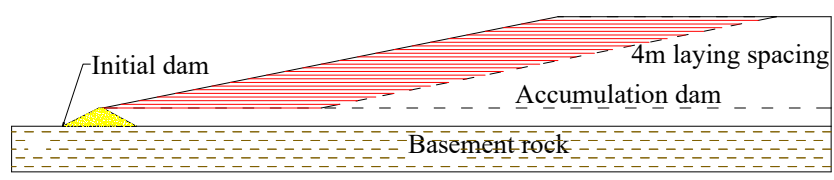

(d)The laying spacing is $4 \mathrm{~m}$

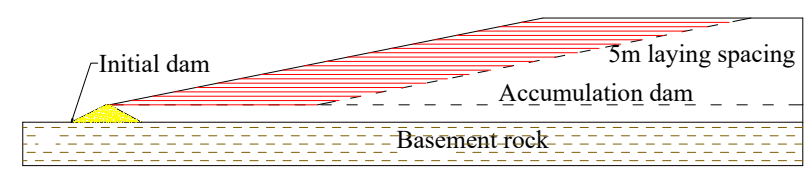


(e)The laying spacing is $5 \mathrm{~m}$

Figure 4 Reinforced tailings dam with different spacing of reinforcement

\subsection{Orthogonal test results and analysis}

\section{(1) Analysis of range results}

The numerical calculation results of 25 groups of orthogonal design schemes are shown in Table 3.

Table 3 Calculation results of orthogonal test design scheme

\begin{tabular}{|c|c|c|c|c|c|c|c|}
\hline $\begin{array}{l}\text { Design } \\
\text { scheme }\end{array}$ & $E / \mathrm{GPa}$ & $L / \mathrm{m}$ & $d / \mathrm{m}$ & $c_{\mathrm{if}} / \mathrm{kPa}$ & $\varphi_{\mathrm{if}} /{ }^{\circ}$ & Blank column & $F$ \\
\hline 1 & 0.5 & 120 & 1 & 5 & 10 & 1 & 2.18 \\
\hline 2 & 0.5 & 150 & 2 & 10 & 15 & 2 & 2.23 \\
\hline 3 & 0.5 & 180 & 3 & 15 & 20 & 3 & 2.29 \\
\hline 4 & 0.5 & 210 & 4 & 20 & 25 & 4 & 2.31 \\
\hline 5 & 0.5 & 240 & 5 & 25 & 30 & 5 & 2.30 \\
\hline 6 & 4 & 120 & 2 & 15 & 25 & 5 & 2.21 \\
\hline 7 & 4 & 150 & 3 & 20 & 30 & 1 & 2.27 \\
\hline 8 & 4 & 180 & 4 & 25 & 10 & 2 & 2.36 \\
\hline 9 & 4 & 210 & 5 & 5 & 15 & 3 & 2.23 \\
\hline 10 & 4 & 240 & 1 & 10 & 20 & 4 & 2.45 \\
\hline 11 & 7.5 & 120 & 3 & 25 & 15 & 4 & 2.25 \\
\hline 12 & 7.5 & 150 & 4 & 5 & 20 & 5 & 2.21 \\
\hline 13 & 7.5 & 180 & 5 & 10 & 25 & 1 & 2.23 \\
\hline 14 & 7.5 & 210 & 1 & 15 & 30 & 2 & 2.46 \\
\hline 15 & 7.5 & 240 & 2 & 20 & 10 & 3 & 2.49 \\
\hline 16 & 11 & 120 & 4 & 10 & 30 & 3 & 2.22 \\
\hline 17 & 11 & 150 & 5 & 15 & 10 & 4 & 2.21 \\
\hline 18 & 11 & 180 & 1 & 20 & 15 & 5 & 2.45 \\
\hline 19 & 11 & 210 & 2 & 25 & 20 & 1 & 2.45 \\
\hline 20 & 11 & 240 & 3 & 5 & 25 & 2 & 2.42 \\
\hline 21 & 15 & 120 & 5 & 20 & 20 & 2 & 2.20 \\
\hline 22 & 15 & 150 & 1 & 25 & 25 & 3 & 2.37 \\
\hline
\end{tabular}




\begin{tabular}{cccccccc}
\hline $\begin{array}{c}\text { Design } \\
\text { scheme }\end{array}$ & $E / \mathrm{GPa}$ & $L / \mathrm{m}$ & $d / \mathrm{m}$ & $c_{\mathrm{if}} / \mathrm{kPa}$ & $\varphi_{\mathrm{if}} /{ }^{\circ}$ & Blank column & $F$ \\
\hline 23 & 15 & 180 & 2 & 5 & 30 & 4 & 2.31 \\
24 & 15 & 210 & 3 & 10 & 10 & 5 & 2.42 \\
25 & 15 & 240 & 4 & 15 & 15 & 1 & 2.49 \\
\hline
\end{tabular}

The numerical calculation results of reinforcement of tailings accumulation dam under different working conditions are analyzed by range method. The range analysis results are shown in Table 4. According to size of the order of range $\mathrm{R}$ in the table, It can be got that the sensitivity order of influencing factors in reinforced tailings dam 5 can be obtained as follows: laying length $(L)>$ laying spacing $(d)>$ elastic modulus $(E)>$ pseudo-cohesion $\left(c_{\text {if }}\right)>$ pseudo friction angle $\left(\varphi_{\mathrm{if}}\right)$; The optimal scheme obtained from range analysis is $L 5 d 1 E 5 c_{\mathrm{if}} 5 \varphi_{\mathrm{if}} 1$.In order to verify the accuracy of the optimal design scheme, $L 5 d 1 E 5 c_{\text {if }} 5 \varphi_{\text {if }} 1$ design scheme is used as the reinforcement scheme of tailings accumulation dam. It is calculated that the safety factor of reinforced tailings dam this moment is 2.58 (see Figure 5), and the calculation result is greater than that of any group of 25 schemes, which further proves the accuracy of range analysis results.

Figure5 Cloud chart of stability calculation of reinforced tailings dam with excellent scheme

Table 4 Range analysis results

\begin{tabular}{ccccccc}
\hline Parameter & $E /(\mathrm{kN} / \mathrm{m})$ & $L / \mathrm{m}$ & $d / \mathrm{m}$ & $c_{\mathrm{i} f} / \mathrm{kPa}$ & $\varphi_{\mathrm{if}} /{ }^{\circ}$ & $\begin{array}{c}\text { Blank } \\
\text { column }\end{array}$ \\
\hline$K_{1 \mathrm{j}}$ & 11.30 & 11.06 & 11.92 & 11.35 & 11.66 & 11.62 \\
$K_{2 \mathrm{j}}$ & 11.52 & 11.29 & 11.68 & 11.55 & 11.64 & 11.67 \\
$K_{3 \mathrm{j}}$ & 11.64 & 11.65 & 11.64 & 11.66 & 11.61 & 11.60 \\
$K_{4 \mathrm{j}}$ & 11.75 & 11.86 & 11.60 & 11.71 & 11.55 & 11.54 \\
$K_{5 \mathrm{j}}$ & 11.79 & 12.15 & 11.17 & 11.74 & 11.56 & 11.58 \\
\hline$k_{1 \mathrm{j}}$ & 2.261 & 2.212 & 2.384 & 2.269 & 2.331 & 2.324 \\
$k_{2 \mathrm{j}}$ & 2.305 & 2.257 & 2.336 & 2.310 & 2.328 & 2.335 \\
$k_{3 \mathrm{j}}$ & 2.329 & 2.329 & 2.328 & 2.333 & 2.321 & 2.319 \\
$k_{4 \mathrm{j}}$ & 2.349 & 2.373 & 2.319 & 2.342 & 2.310 & 2.307 \\
$k_{5 \mathrm{j}}$ & 2.358 & 2.430 & 2.234 & 2.347 & 2.311 & 2.316 \\
\hline Range $R$ & 0.097 & 0.218 & 0.150 & 0.078 & 0.021 & 0.017 \\
\hline susceptibility & & & $L>d>E>c>\varphi$ & & \\
\hline
\end{tabular}


As shown in Figure 6, the variation trend of safety factor of reinforced tailings dam with the level of reinforcement influencing factors is shown.It can be seen from the figure that the levels of elastic modulus $(E)$, laying length $(L)$ and pseudo-cohesion $\left(c_{\text {iff }}\right)$ interface are positively correlated with the overall safety factor, and the levels of laying spacing $(d)$ are negatively correlated with the overall safety factor, while the pseudo friction angle $\left(\varphi_{\mathrm{if}}\right)$ and the number of levels taken in the blank column have no obvious change with the safety factor. In terms of the variation range of the level number taken by these five influencing factors with the safety factor, the variation range of the level number taken by the laying length $(L)$ with the safety factor is the largest, the variation range of the level number taken by the elastic modulus $(E)$ and pseudo-cohesion $\left(c_{\text {iff }}\right)$ with the safety factor is the second, and the pseudo friction angle $\left(\varphi_{\mathrm{if}}\right)$ has the smallest variation range.
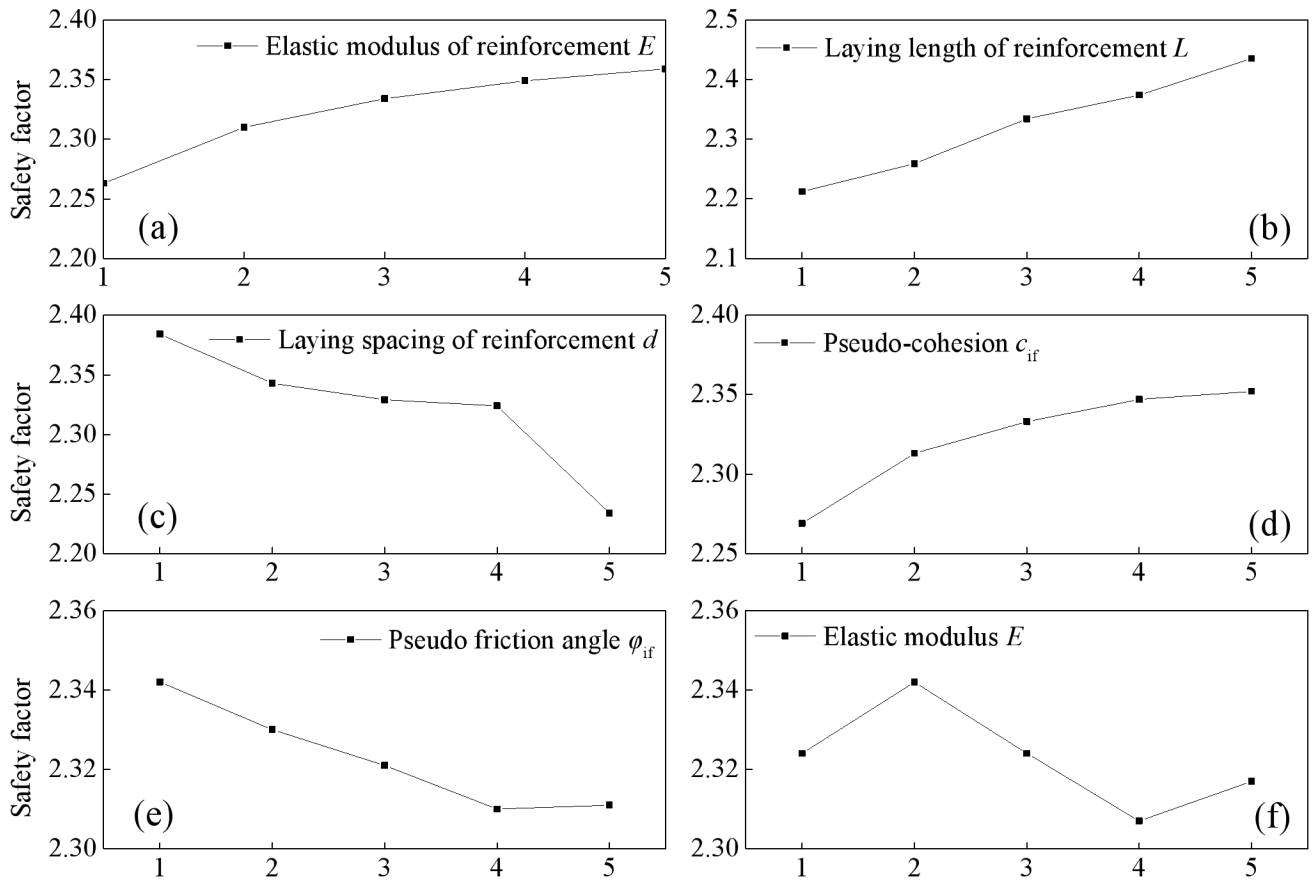

Figure 6 Change trend of safety factor with influence factor level

\section{(2) Analysis of variance results}

The significance of the orthogonal numerical calculation results is tested by the variance method. The variance calculation results are shown in Table 5. Without considering the interaction between influencing factors, the degrees of freedom of each column of the orthogonal table are 4, and the blank column is the random error column. According to the classification method of significance level, the significance levels of $\mathrm{F}$ distribution are 0.1 , 
0.05 and 0.01 respectively. According to the table of $\mathrm{F}$ distribution, F0.1 $=4.11, \mathrm{~F} 0.05=6.39$ and F0.01 $=15.98$. The significant results of five influencing factors of reinforced tailings dam are as follows: the laying length $(L)$ and laying spacing $(d)$ have a very significant influence, the elastic modulus $(E)$ and pseudo-cohesion $\left(c_{\mathrm{if}}\right)$ have a significant influence, and the pseudo friction angle $\left(\varphi_{\mathrm{if}}\right)$ the impact is not very significant.

Table 5 Variance analysis results

\begin{tabular}{cccccc}
\hline $\begin{array}{c}\text { Variance } \\
\text { source }\end{array}$ & $\begin{array}{c}\text { Sum of squares of } \\
\text { deviations }\end{array}$ & Freedom & Variance estimate & $F$ value & Significance \\
\hline$E$ & 0.0307 & 4 & 0.0077 & 14.6612 & $* *$ \\
$L$ & 0.1527 & 4 & 0.0382 & 72.9723 & $* * *$ \\
$d$ & 0.0595 & 4 & 0.0149 & 28.4290 & $* * *$ \\
$c_{\text {if }}$ & 0.0202 & 4 & 0.0051 & 9.6684 & $* *$ \\
$\varphi_{\text {if }}$ & 0.0018 & 4 & 0.0005 & 0.8815 & - \\
Error $e$ & 0.0021 & 4 & 0.0005 & & \\
Sum $\triangle \mathrm{e}$ & 0.2670 & 24 & $F_{0.1}=4.11, F_{0.05}=6.39, F_{0.01}=15.98$ & \\
\hline
\end{tabular}

Note: in the significance column, "***" represents very significant; "**" means significant; "-" means insignificant.

\section{Conclusion}

The single index and multi factor numerical simulation test is designed by orthogonal method, and the elastic modulus $(E)$, laying length $(L)$, laying spacing $(d)$, pseudo-cohesion of reinforcement-tailings interface $\left(c_{\text {if }}\right)$ and pseudo friction angle of reinforcement-tailings interface $\left(\varphi_{\text {if }}\right)$ five influencing factors, $\mathrm{L}_{25}\left(5^{6}\right)$ orthogonal table is designed for 25 groups of calculation schemes. The numerical calculation is carried out by the finite element strength reduction method, the safety factor is determined by the comprehensive criterion, and the sensitivity of the factors affecting the safety and stability of the reinforced tailings dam is analyzed. The sensitivity order of the influencing factors of the stiffened tailings dam is laying length $(L)>$ laying spacing $(d)>$ elastic modulus $(E)>$ pseudo-cohesion $\left(c_{\text {if }}\right)>$ pseudo friction angle $\left(\varphi_{\mathrm{if}}\right)$. The significance test results show that the laying length $(L)$ and laying spacing $(d)$ have a very significant impact, the elastic modulus $(E)$ and pseudo-cohesion $\left(c_{\text {if }}\right)$ have a significant impact, and the pseudo friction angle $\left(\varphi_{\mathrm{if}}\right)$ the impact is not very significant; Among them, the sensitivity ranking of reinforcement influencing factors of range analysis results is consistent with the significance results of analysis of variance, which verifies the 
reliability of numerical simulation results.

\section{REFERENCE}

[1] Deng Hongwei, Ye Mao and Wu Yanlin (2016) Numerical simulation and sensitivity study of lens based on GMS and slide. Journal of Safety and Environment, 16(01):91-94, https//doi.org/10.13637/j.issn.1009-6094.2016.01.020.

[2] Du Changbo and Yi Fu. (2021) Analysis of interfacial pullout behavior of a geosynthetic reinforced soil.Journal of Disaster Prevention and Mitigation Engine, 41(01):85-90+109.

[3] Lin Jie, Shen Zhenzhong, man Jianming (2020) Study on the influence of geotechnical mat on the stability of tailings dam. Mining Research and Development, 40(11):28-32.

[4] Liu C, Shen Z, Gan L (2018) The seepage and stability performance assessment of a new drainage system to increase the height of a tailings dam. Applied Sciences, 8(10):1840, https//doi.org/10.3390/app8101840.

[5] Ning Zhangxuan, Feng Meisheng, Wang fengjiang (2010) Triaxial compression test of multi-layer reinforced tailings. Rock and Soil Mechanics, 31(12):3784-3788, https//doi.org/10.3969/j.issn.1000-7598.2010.12.015.

[6] Tan Qinwen, Xin Baoquan, Wan Lu (2018) Risk assessment index and classification method of major hazard sources in tailings pond.Journal of Safety Science and Technology, 14(07):99-106, https//doi.org/CNKI:SUN:LDBK.0.2018-07-016.

[7] Wang Hanxun, Zhang Bin, Zhang Zhongjian (2018) Stability analysis of iron ore tailings dam under seepage and earthquake. Geology and Exploration, 54(03):614-622, https//doi.org/CNKI:SUN:DZKT.0.2018-03-018.

[8] Wang wensong, Yin Guangzhi, Wei zuoan (2017) Dynamic response and stability analysis of upstream damming of fine tailings in high intensity seismic area. Chinese Journal of Rock Mechanics and Engineering, 36(05):1201-1214, https//doi.org/10.13722/j.cnki.jrme.2016.1221.

[9] Wei zuoan, Xu Jiajun, Chen Yulong (2014) Reinforcement of tailings accumulation dam with end reel geogrid. Journal of Northeastern University (Natural Science), 35(06):880884, https//doi.org/10.3969/j.issn.1005-3026.2014.06.027.

[10] Xie Yuanding, Wu genglin, Jin Xiaoguang (2014) Stability analysis of accumulation dam of Wujiagou tailings pond. The Chinese Journal of Geological Hazard and Control, 25(03):49-55, https//doi.org/CNKI:SUN:ZGDH.0.2014-03-009.

[11] Yang Chunhe, Zhang Chao, Li Quanming (2021) Catastrophe mechanism and prevention 
and control methods of large high tailings dam. Rock and Soil Mechanics, 42(01):1-17, https//doi.org/10.16285/j.rsm.2020.1653.

[12] YI Fu, DU Changbo, WANG Zhengyu (2020) Effects of mesh size on interface characteristics between geogrid and tailings. Journal of China Coal Society, 45(05):17951802, https//doi.org/10.13225/j.cnki.Jccs.2019.0528.

[13] Yi Fu, Du Changbo, Li Jun (2019) Study on rheological model of tailings reinforced with viscoelastic plastic geogrid. Journal of Civil and Environmental Engineering, 41(06):5260, https//doi.org/CNKI:SUN:JIAN.0.2019-06-007.

[14] Yin G, Wang W, Wei Z, Cao G, \& Jin X (2018) Analysis of dynamic response and seismic behavior of tailings dam for heightening and expansion.Chinese Journal of Rock Mechanics and Engineering, 37(S1):3132-3142, https//doi.org/10.13722/j.cnki.jrme.2016.1363

[15] Yu S Y, Shao L T and Liu S Y (2013) Stability analysis of tailings dam based on finite element limit equilibrium method. Rock and Soil Mechanics, 34(4):1185-1190.

[16] Zhang duo, Liu Yang, Wu shunchuan (2014) Failure mechanism analysis of tailings dam slope based on discrete continuous coupling.Chinese Journal of Geotechnical Engineering, 36(08):1473-1482.

[17] Zhang Qiangui, Wang Yameng, Li Guangzhi (2015) Particle flow numerical simulation of micromechanical mechanism of tailings dam deformation. Journal of Chongqing University, 38(03):71-79, https//doi.org/ 10.11835/j.issn.1000-582X.2015.03.010.

[18] Zheng Binbin, Zhang Dongming, Wang Hao (2019) Experimental study on mechanical properties of basalt fiber reinforced tailings. China Safety Science Journal, 29(03):114119, https//doi.org/CNKI:SUN:ZAQK.0.2019-03-023. 